\title{
Aplasia of the Posterior Arches of the Atlas: A Presentation of One Case
}

\author{
Mohamed Ali Rekik*, Fethi Kraiem, Imed Trigui, Kamel Khardani and Slim Dhahak \\ Department of Orthopaedic Surgery, FSI hospital La Marsa, Tunisia \\ *Corresponding author: Mohamed Ali Rekik, Department of Orthopaedic Surgery, FSI hospital La Marsa, Tunis, Tunisia
}

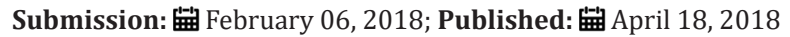

\begin{abstract}
Introduction: Partial or complete aplasia of the posterior arches of the atlas is a well-documented anomaly but a relatively rare condition caused by a defect in their closure. This condition is usually asymptomatic so most are diagnosed incidentally.

Case report: We report the case of a patient who presents a defect of the posterior arch of atlas.

Conclusion: There is a variety of the congenital defects of the arch of the atlas. Further studies are required on these lesions in order to take possible protection measures against trauma, and the selection between conservative or surgical treatment.
\end{abstract}

Keywords: Atlas; Aplasia; Posterior arche

\section{Introduction}

Congenital defect of the posterior arch of the atlas is a rare condition ( $<4 \%$ among the population [1]) but its characteristics have been well described. Usually associated with some type of syndrome, such as Klippel-Feil, Turner, Di Giorge or Arnold-Chiari, and also with other alterations of the axial skeleton (torticollis, spina bifida, short neck, etc.,) [2,3], so their presence in healthy patients is rare. Currarino et al. [4] classified defects in the posterior arches of the atlas into different degrees, as shown in Table 1. We present a case of Currarino type D congenital aplasia of the posterior arches of the atlas.

Table 1: Currarino's morphologic classification for C1.

\begin{tabular}{|c|c|}
\hline Type & Description \\
\hline A & Failure of posterior midline fusion of the two hemiarches \\
\hline B & Unilateral defect \\
\hline C & Bilateral defects \\
\hline D & $\begin{array}{c}\text { Absence of posterior arch, with persistent posterior } \\
\text { tubercle }\end{array}$ \\
\hline E & Absence of the entire arch, including the tubercle \\
\hline
\end{tabular}

\section{Case Report}

A 28-year-old woman with no previous relevant History was referred to the emergency of Orthopedic Surgery at the hospital FSI Marsa after being involved in a traffic accident complained of pain at the front of her neck, but of no neurologic symptoms in the limbs. On physical examination, she had generalized tenderness over her cervical spine and a pain particularly in the flexion/extension of the neck. Her neurologic system showed no abnormal findings.
Simple radiography $(\mathrm{Rx})$ revealed the existence of a partial defect in the posterior arch of $\mathrm{C} 1$ with a preserved posterior tubercle (Currarino type D) (Figure 1). We verified the stability of the tubercle through radiography in flexion and extension (Figure 2). Computed tomography (CT) images with three-dimensional (3D) reconstruction demonstrated the absence of the posterior arch and the presence of a persistent posterior tubercle (Figure 3). No evidence of compression of the spinal cord was shown on magnetic resonance imaging (Figure 4). The patient benefited from a symptomatic treatment with anti-inflammatory and analgesic drugs. Her symptoms decreased within 48 hours. She was asked to avoid contact sports, athletic activities and any activity or situation which could cause the cervical hyperextension.

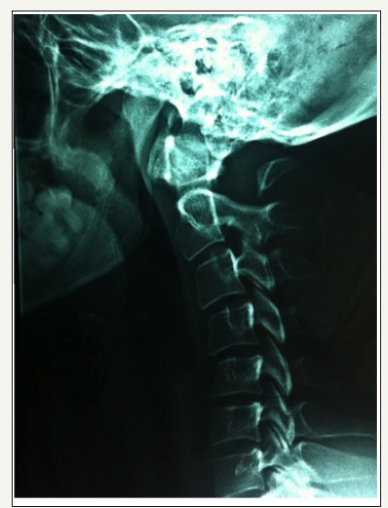

Figure 1: Lateral radiograph of the cervical spine showed a defect in the posterior arch of the atlas, with persistent posterior tubercle. 


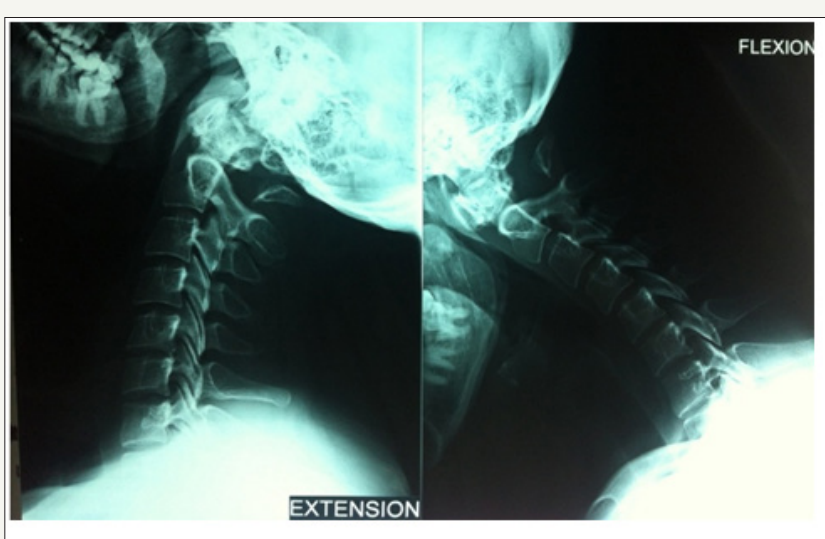

Figure 2: Flexion and extension radiographs showing absence of the posterior arch of the atlas without evidence of atlatoaxial instability.

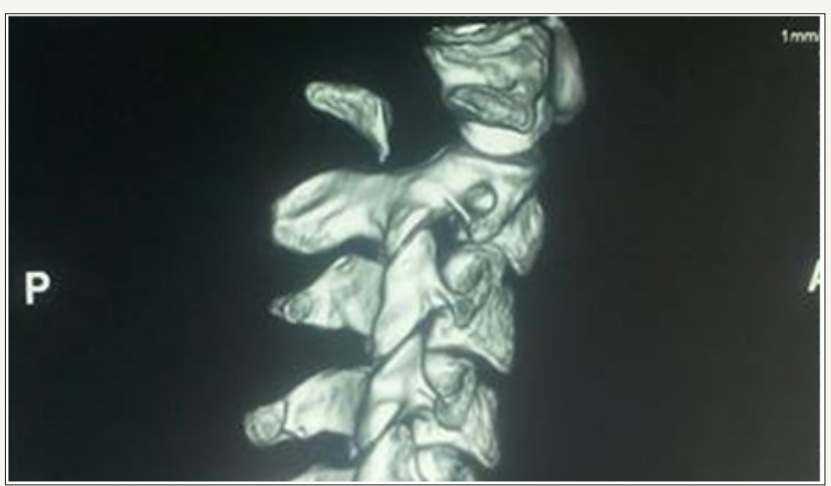

Figure 3: 3D CT scan showing absence of the posterior arch and the presence of a persistent posterior tubercle.

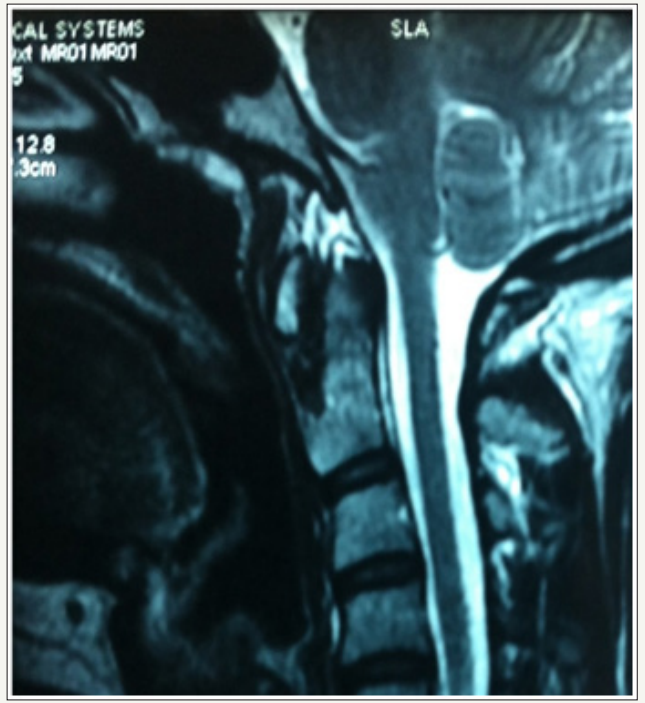

Figure 4: Sagittal T2-weighted magnetic resonance imaging revealing no compression of the spinal cord.

\section{Result}

The evolution of the patient is satisfactory.

\section{Discussion}

Alterations of the posterior arch of the atlas are rare $(<4 \%)$. This is especially true of type D cases, such as the case presented in this work, which have a prevalence under $0.2 \%$ [1]. When not associated with a syndrome (Down, Turner, Di Giorge, etc.), these patients are usually asymptomatic and the finding is incidental [5], mostly due to imaging studies performed after trauma or chronic neck pain. Computed tomography is useful to confirm the diagnosis and differentiate it from fractures in particular the fracture typifies Jefferson. Magnetic resonance imaging is reserved for cases where any neurologic abnormality is observed or there is a suspicion of myelopathy.

Regarding treatment, the literature contains reports supporting different opinions. Some authors recommend treating all patients who retain the posterior tubercle by removing it, thus avoiding the risk of impaction on the spinal cord [6], whilst others support conservative treatment, with or without preventive measures, reserving surgery only for those cases with clear and proven symptoms due to compression by the tubercle or atlanto-axis instability [4]. In our case, we decided to follow a conservative treatment, avoiding situations of risk, since there were no spinal alterations or signs of instability. We consider that, as a general rule, excision of the tubercle is overly aggressive in patients with no symptoms and may even cause instability.

\section{Conclusion}

We believe that abnormalities of the posterior arches of the atlas are rare and usually asymptomatic, although potentially dangerous for the spine. Unfortunately, the literature is scarce and with a low level of evidence. Therefore, we believe it would be interesting to study more cases, in order to establish the possible indications for surgery and the usefulness of preventive measures.

\section{References}

1. Senoglu M, Safavi-Abbasi S, Theodore N, Bambakidis NC, Crawford NR, et al. (2007) The frequency and clinical significance of congenital defects of the posterior and anterior arch of the atlas. J Neurosurg Spine 7(4): 399-402.

2. Dubousset J (1986) Torticollis in children caused by congenital anomalies of the atlas. J Bone Joint Surg Am 68(2): 178-188.

3. Hensinger R (1986) Osseus anomalies of the craniovertebral junction. Spine 11(4): 323-333.

4. Currarino G, Rollins N, Diehl JT (1994) Congenital defects of the posterior arch of the atlas: a report of seven cases including an affected mother and son. AJNR Am J Neuroradiol 15(6): 249-254.

5. Pasku D, Katonis P, Karantanas A, Hadjipavlou A (2007) Congenital posterior atlas defect associated with anterior rachischisis and early cervical degenerative disc disease: a case study and review of the literature. Acta Orthop Belg 73(2): 282-285.

6. Torreman M, Verhagen IT, Sluzewski M, Kok AJ, Van Rooij WJ (1996) Recurrent transient quadriparesis after minor cervical trauma associated with bilateral partial agenesis of the posterior arch of the atlas. J Neurosurg 84(4): 663-665. 
Creative Commons Attribution 4.0 International License

For possible submissions Click Here

Submit Article

\section{RISM I \\ Research \& Investigations in Sports Medicine}

\section{Benefits of Publishing with us}

- High-level peer review and editorial services

- Freely accessible online immediately upon publication

- Authors retain the copyright to their work

- Licensing it under a Creative Commons license

- Visibility through different online platforms 